\title{
Relação entre Desempenho Financeiro e Evidenciação Socioambiental à Luz do Modelo de Epstein e Roy \\ Relation Between Financial Performance and Socio-Environmental Disclosure in the Light of the Epstein and Roy Model
}

\author{
Emily Tavares Pessoa Maciel ${ }^{1}$ \\ Francisco José da Silva Júnior ${ }^{2}$ \\ Maria Luiza Farias Diniz ${ }^{3}$ \\ Aldo Leonardo Cunha Callado ${ }^{4}$
}

\section{Resumo}

Esta pesquisa buscou verificar a relação entre desempenho financeiro e o nível de evidenciação socioambiental de empresas brasileiras, entre 2007 e 2017. Analisou-se 30 empresas utilizando o modelo adaptado de Epstein e Roy (2003), que verifica as evidenciações socioambientais nas dimensões: ambiental, saúde e segurança, comunidade e empregados. Para o desempenho financeiro utilizou-se o modelo de Epstein e Roy (2001), que indica o retorno sobre investimento (ROI), o retorno sobre o capital empregado (ROCE) e o valor econômico adicionado (EVA) como indicadores financeiros de longo prazo. Por meio de análise de dados em painel, estimou-se quatro regressões que buscaram confirmar as hipóteses de que o nível de evidenciação sustentável poderia influenciar as variáveis de desempenho financeiro em período posterior; assim como se o desempenho financeiro é fator determinante para os níveis de evidenciação de sustentabilidade nos períodos seguintes. Verificou-se que o EVA não apresentou relação significativa com o nível de divulgação, não exercendo influência sobre a evidenciação da empresa. Já as variáveis ROI e ROCE apresentaram relação com o nível de divulgação socioambiental, demonstrando que quanto mais se evidencia informações sustentáveis, maiores serão as possibilidades de retorno sobre o capital empregado e sobre o capital investido. Além disso, frente ao aumento da variável ROI, as empresas demonstraram maior determinação em divulgar informações socioambientais. Desse modo, constatou-se efetividade da perspectiva de Epstein e Roy, ao observar que demonstrar sustentabilidade impulsiona maiores retornos sobre o capital investido e empregado, assim como o capital investido tende a otimizar os níveis de divulgação sustentável.

Palavras-chave: Sustentabilidade Empresarial. Desempenho Financeiro. Indicadores Financeiros.

\section{Abstract}

This research sought to verify the relationship between the financ ial performance and the level of socio-environmental disclosure of Brazilian companies, between 2007 and 2017. 30 companies were analyzed using the model adapted from Epstein and Roy (2003), which verifies the socio-environmental disclosures in the dimensions: environmental, health and safety, community, and employees. For financial performance, the Epstein and Roy model (2001) was used, which indicates the return on investment (ROI), the return on capital employed (ROCE) and the economic added value (EVA) as long-term financial indicators. term. Through panel data analysis, four regressions were estimated that sought to confirm the hypotheses that the level of sustainable disclosure could influence the variables of financial performance in a later period; as well as whether financial performance is a determining factor for the levels of sustainability disclosure in the following periods. It was found that the EVA did not show a significant relationship with the level of disclosure, not influencing the company's disclosure. The ROI and ROCE variables were related to the level of socio-environmental disclosure, demonstrating that the more sustainable information becomes evident, the greater the possibilities of return on employed capital and invested capital. In addition, in view of the increase in the ROI variable, companies have shown greater determination to disclose socio-environmental information. Thus, the effectiveness of Epstein and Roy's perspective was observed, when observing that demonstrating sustainability drives greater returns on invested and employed capital, just as invested capital tends to optimize levels of sustainable disclosure.

Keywords: Corporate Sustainability. Financial Performance. Financial indicators.

Manuscript first received/Recebido em: 10/06/2020

Manuscript accepted/Aprovado em: 30/06/2021

\footnotetext{
${ }^{1}$ Mestre em Ciências Contábeis. Professora Substituta do Curso de Bacharelado em Administração da Universidade Federal do Piauí (UFPI). Picos, Piauí, Brasil. E-mail: emilytavares@ymail.com.

2 Mestre em Ciências Contábeis. Assistente Administrativo da Prefeitura Municipal de Sousa. João Pessoa, Paraíba, Brasil. E-mail: fjsilvajunior@hotmail.com.

${ }^{3}$ Mestre em Ciências Contábeis. Bancária na Instituição Financeira Bradesco. João Pessoa, Paraíba, Brasil. E-mail: luiza farias@hotmail.com.

4 Doutor em Agronegócios. Professor nos Programas de Pós-Graduação em Administração (PPGA) e em Ciências Contábeis (PPGCC) da Universidade Federal da Paraíba e no Programa de Pós-Graduação em Controladoria (PPGC) da Universidade Federal Rural de Pernambuco. João Pessoa, Paraíba, Brasil. E-mail: aldocallado@yahoo.com.br.
} 


\section{INTRODUÇÃO}

No decorrer dos anos, conceitos associados ao meio ambiente e sustentabilidade apresentaram diferentes vertentes, que variam de teorias voltadas exclusivamente para aspectos sociais, ambientais ou simplesmente para os financeiros. A sustentabilidade nos últimos anos tem sido apontada como a solução para os problemas que o meio ambiente vem vivenciando, tornando o relacionamento homem versus natureza menos invasivo (Silva, 2014).

A consciência ambiental tem aumentado gradativamente e vem assumindo dimensões maiores, influenciando empresas e consumidores a refletirem sobre o papel das organizações no controle do uso dos bens naturais, a fim de proporcionar sustentabilidade ambiental e, por conseguinte, sustentabilidade organizacional (Gao \& Zhang, 2015). Com isto, os gestores tendem a evidenciar tal preocupação, a partir de seus demonstrativos como forma de sinalizar percepções pertinentes sobre questões socioambientais.

Tempos atrás, as organizações não se preocupavam tanto com o desenvolvimento sustentável, principalmente pela dificuldade de se adotar posturas sustentáveis (Mcdonagh, 1998). Acreditava-se que seguir a linha do desenvolvimento sustentável seria mais dispendioso. Com o passar dos anos, a premissa de que se tornar sustentável teria um custo alto foi se alterando. Independente de toda a ênfase dada ao assunto, o descaso do ser humano com o meio ambiente é fácil de ser percebido. $E$, com relação a determinados tipos de atividades, para algumas organizações foi necessária a criação de legislações capazes de inibir e em alguns casos punir, e só assim fazer com que as empresas começassem a ponderar e controlar as suas ações relacionadas ao meio ambiente (Silva, 2014).

A pressão do governo e da sociedade para que empresas adotem políticas que não prejudiquem o meio ambiente tem feito com que a elaboração dos relatórios represente vantagem competitiva, diante do surgimento de um grupo de consumidores que procuram comprar produtos apenas de empresas reconhecidas por sua relação com o meio ambiente (Bonsón \& Bednarova, 2015).

Com o advento de legislações que versam sobre políticas sustentáveis, juntamente com a preocupação de se manter em um mercado por um longo prazo, as organizações começaram a desenvolver ações voltadas à sustentabilidade, adaptando os seus processos observando que os investimentos realizados hoje em relação aos aspectos ambientais serão recompensados no decorrer dos anos (Spezamiglio, Galina \& Calia, 2016).

De acordo com Consoni, Colauto e Lima (2017) as empresas que praticam a sustentabilidade têm uma maior oportunidade de obter sucesso no futuro, mantendo-se ativas por muitas décadas e gerações, e não apenas por alguns meses. Com isto, notase que preocupar-se com questões sustentáveis possivelmente trará benefícios futuros. A consciência da essencialidade de tornar-se sustentável tende a advir das experiências passadas das empresas, que quanto maior for a percepção da sua importância, maior tenderá a ser o investimento no quesito ambiental. 
Investir em sustentabilidade é uma ação cujo resultado só irá aparecer com o decorrer do tempo; portanto, as empresas que desejam permanecer no mercado tendem a seguir por essa linha e caminhar para atingir os objetivos de forma mais sustentável. $\mathrm{O}$ ponto central do entendimento de problemas ecológicos advém da relação entre o desempenho econômico e o meio ambiente, que originou o conceito de sustentabilidade (Coelho, Coelho \& Godoi, 2013).

Uma das formas das empresas demonstrarem interesse associado à sustentabilidade é a partir da divulgação de relatórios que retratam as suas práticas e ações em relação ao meio em que estão inseridas. Uma ferramenta importante que pode ser utilizada pelas organizações são os relatórios de sustentabilidade que analisam a evolução das empresas de acordo com as dimensões de sustentabilidade (Nogueira \& Faria, 2012). Acredita-se que o desempenho financeiro das empresas tende a aumentar juntamente com o seu interesse em se inserir no contexto da sustentabilidade, criando assim a percepção de que quanto maior for a evidenciação do nível de conscientização em questões socioambientais aos potenciais usuários da informação, maiores serão as chances de se obter retornos crescentes.

As empresas têm utilizado vários indicadores para ajudar a quantificar os esforços feitos para melhorar o desempenho da sustentabilidade (Epstein \& Roy, 2001). Os indicadores de desempenho devem ser desenvolvidos no sentido de poder avaliar e monitorar o valor desenvolvido das ações de sustentabilidade.

Corriqueiramente, encontram-se usuários e/ou partes interessadas, sejam internos ou externos, que têm anseios em compreender e analisar as empresas a partir das informações que são disponibilizadas. Observa-se uma atual demanda por parte dos consumidores, de avaliarem diferentes aspectos das organizações, acompanhando as suas produções aliando-as ao consumo sustentável (Kruter, Barcellos \& Silva, 2012).

Para Epstein e Roy (2001), o desempenho financeiro é capaz de identificar o interesse das empresas em busca da sustentabilidade no longo prazo; ou seja, as estratégias sociais, ambientais e econômicas também visam ações específicas e seus retornos, tanto para a empresa como para a sociedade. Diante disso, a presente pesquisa busca responder ao seguinte questionamento: Qual é a relação dos resultados financeiros e dos níveis de evidenciação socioambiental das empresas brasileiras de capital aberto?

O estudo traz como diferencial investigar a relação entre o desempenho financeiro e os níveis de sustentabilidade propostos por Epstein e Roy, em empresas brasileiras de capital aberto listadas no Guia de Sustentabilidade da Revista Exame, buscando relacionar os interesses das organizações com a sustentabilidade e o desempenho de longo prazo das organizações.

De acordo com a perspectiva de Epstein e Roy (2001), o desempenho da sustentabilidade é verdadeiramente importante, e suas avaliações e recompensas merecem destaque. As empresas que mantem interesse e querem mudar a sua cultura organizacional, e dessa forma melhorar o desempenho social e ambiental, devem tornar a sustentabilidade parte integrante da sua avaliação de desempenho. 
Por meio dos resultados, pôde-se observar que tais empresas que compuseram a amostra, ao aumentar os retornos sobre o investimento (ROI) tendem a investir no aumento dos níveis de sustentabilidade, e com isto, possibilita um aumento nos níveis de retorno sobre o capital empregado (ROCE) e nos retornos sobre o investimento (ROI) de tais empresas.

\section{REFERENCIAL TEÓRICO}

\subsection{Sustentabilidade Empresarial e Desempenho Financeiro}

Com a gravidade e o aumento dos problemas relacionados ao meio ambiente após a industrialização, juntamente com a preocupação das empresas em conquistar um lugar no mercado no longo prazo, surge o interesse em utilizar práticas sustentáveis e observar todos ao seu redor, visando um crescimento econômico associado à preservação ambiental e preocupação social (Silva, 2014).

De acordo com Coelho et al. (2013) a sustentabilidade está relacionada à operacionalização da empresa que não cause lesão aos seres humanos e não destruam o meio ambiente e sim enriqueça-o e fortaleça-o. Alcançar o desenvolvimento sustentável é uma tarefa minuciosa, pois é necessário estabelecer metas, valores, princípios e um bom planejamento. Ser sustentável é complexo, visto que o que hoje é comercializado e requisitado, amanhã pode já não ser mais. Diante desse contexto, manter-se estável e em equilíbrio é uma tarefa difícil.

Infere-se que, para a organização obter êxito, a mesma precisa considerar posicionamento de seus participantes e colaboradores. As informações geradas por esses agentes permitem melhoria no desenvolvimento e na sustentabilidade da empresa a um custo mínimo e com possíveis ganhos nos negócios (Lokuwaduge \& Heenetigala, 2017).

Relata-se que as entidades ainda fraquejam ao descrever as suas práticas sustentáveis, pelo simples fato de não conviverem harmônica e naturalmente com essas condutas. Muito ainda precisa ser aprimorado no contexto organizacional para que consigam observar que o investimento para seguir essa conduta será compensado no longo prazo (Mcdonagh, 1998). Segundo Pimenta (2010) algumas empresas brasileiras encaram a sustentabilidade como um entrave para o seu desenvolvimento empresarial, esquivandose das oportunidades que a sustentabilidade pode oferecer.

Como retratado, para que as organizações se tornem sustentáveis, as suas ações devem partir de dentro para fora da empresa, e é necessário obter o comprometimento de todas as partes envolvidas no processo. Acreditar que a entidade pode vir a ser sustentável, deve se sobressair para todos, sendo um processo contínuo, o qual poderá gerar algum tipo de retorno, seja financeiro ou não, com o decorrer dos anos.

Existem diversas ramificações da sustentabilidade, palavra que antes era pouco usada, mas que hoje se destaca entre as outras, estendendo o seu uso para diferentes áreas, se referindo a um conjunto de conceitos, que circundam entre crescimento 
econômico, crescimento financeiro e a preocupação latente com a parte ambiental e social da organização.

Munck e Souza (2009) inferem que as organizações podem ser classificadas em três tipos, a saber: as organizações economicamente sustentáveis, que garantem uma liquidez necessária em qualquer período; as ecologicamente sustentáveis, que englobam as que não causam danos ao ecossistema em geral; e as socialmente sustentáveis, que envolvem o capital humano dos seus parceiros e incrementam a sociedade em geral.

Portanto, a sustentabilidade organizacional voltada para a conservação é um padrão que existe um interesse por equilibrar questões econômicas, sociais e ambientais, todas colocadas em um mesmo patamar de importância. As iniciativas relacionadas a essa sustentabilidade organizacional vão além das conformidades legais e não se limitam apenas a preocupações associadas ao lucro. A motivação para o desenvolvimento da sustentabilidade organizacional também está no potencial humano, na responsabilidade social das empresas e no cuidado com o planeta (Kansal, Joshi \& Batra, 2014).

A dimensão ambiental contempla o crescimento organizacional ecologicamente correto, a qualidade do meio ambiente e preservação dos recursos, pensando nas novas gerações, no que se refere à utilização sensata dos recursos naturais, sem destruir o meio ambiente e sem afetar as pessoas que estão ao seu redor (Epstein \& Roy, 2003). De acordo com Silva et al., (2013), as empresas precisam diminuir o uso dos combustíveis fósseis, potencializar a eficácia dos recursos utilizados para proteger a biodiversidade e fomentar a política de desenvolvimento de fontes de energias renováveis.

Na dimensão econômica, o objetivo dar-se por desenvolver bem os produtos que possam atender as outras dimensões (ambiental e social) do modo mais economicamente viável (Epstein \& Roy, 2003). Nesta dimensão, encontra-se a preocupação com relação ao mercado competitivo, quando a empresa busca sucesso econômico, mas observando também o meio ambiente e a sociedade.

A dimensão social está associada aos relacionamentos que envolvem as pessoas dentro e fora da organização; considerando as condições destas em relação à determinada informação, buscando a distribuição igualitária e uma sociedade mais justa em suas ações, de modo a melhorar os direitos e as condições dessa massa populacional, reduzindo também a distância entre os padrões de vida (Epstein \& Roy, 2003).

Consegue-se identificar diversas vertentes para a aplicação do termo: sustentabilidade. Utiliza-se no meio social, no econômico e no ambiental, empregando-o principalmente quando se deseja que algo subsista e seja promissor, pois, com o passar dos anos e com a evolução industrial, muitas organizações começaram a ter interesse por um crescimento financeiro, preocupando-se com todos ao seu redor (meio ambiente e sociedade) e observando que essa preocupação pode ser o seu diferencial de sobrevivência no futuro.

A relação entre os esforços de sustentabilidade de uma empresa e seu desempenho financeiro tem ganhado crescente interesse entre a academia e a imprensa nos últimos anos (Patari, Jantune, Kylaheiko \& Sandstrom, 2011). 
Para Weber, Scholz e Michalik (2010) o desenvolvimento sustentável das organizações está associado diretamente ao seu desempenho financeiro, para os autores, a sustentabilidade pode ser usada como determinante para o desempenho corporativo financeiro subsequente da empresa.

Orlitzky, Schmidt e Rynes (2003) apontam que o desempenho financeiro das organizações tende a ser mensurado de três formas, com relação às medidas de mercado, ou seja, retorno para o investidor, com relação às medidas contábeis, retorno contábil, e com relação a medidas percentuais, surveys. Pereira, Stocker, Mascena e Boaventura (2020) detalham que as medidas de mercado correspondem aos preços das ações das empresas e ao resultado de alguns indicadores como ROI, ROCE e EVA capazes de refletir a satisfação dos investidores e capturar a eficiência financeira interna; as medidas contábeis são capazes de refletir a eficiência interna da organização e o survey a performance financeira baseada em estimativas subjetivas.

A contabilidade proporciona diversas informações capazes de externar o desempenho financeiro das organizações, graças aos seus relatórios, documentos e dados, tais informações servem como ferramenta para auxiliar os gestores na tomada de decisões no contexto empresarial (Silva, Floriani \& Hein, 2018).

A análise do desempenho financeiro da organização faz-se necessária para entender como anda a organização frente os seus concorrentes, ao mercado e comparando também às projeções feitas pela alta gestão, a fim de conseguir pontuar os possíveis erros e acertos da administração da empresa.

Kaplan e Northon (1997) relatam que o desempenho financeiro das organizações pode ser medido de diversas formas e ajustado frente às necessidades do gerenciamento estratégico de cada organização. As organizações são únicas e apresentam características e necessidades distintas, a análise de seu desempenho financeiro também deve moldar-se à sua realidade, sendo coerente com as suas perspectivas, funções e perfis.

\subsection{Evidenciação por Relatórios}

Os relatórios agrupam os dados registrados pela organização, tanto monetários quanto não monetários, disponibilizando-os aos potenciais usuários da informação (Marion, 2015). Elaborar relatórios também abrange identificar, mensurar e divulgar o desempenho sustentável das empresas.

Com a elaboração e divulgação desses relatórios, é possível identificar quais as organizações estão mais coerentes com o interesse dos seus stakeholders, pois, a partir deles, podem-se verificar as metas organizacionais, bem como suas práticas em toda a empresa; não focando apenas no desempenho econômico-financeiro, mas também se preocupando em expor seu envolvimento com o social e o ambiental (Lokuwaduge \& Heenetigala, 2017).

Um dos relatórios conhecidos com o propósito de elevar as práticas de sustentabilidade, baseadas no interesse público, nos relatórios de sustentabilidade de empresas a um nível 
de qualidade similar aos relatórios financeiros já existentes é o GRI (Global Reporting Initiative).

Mais de 60 (sessenta) países adotaram o GRI como modelo de relatório. A Global Reporting Initiative é uma organização internacional não governamental que auxilia as empresas na elaboração e compreensão dos relatórios voltados à sustentabilidade. Esses relatórios surgiram com o intuito de medir o desempenho sustentável das organizações (GRI, 2006).

De acordo com Fernandes, Siqueira e Gomes (2010), para assegurar a veracidade dos relatórios existem alguns princípios, conforme o GRI (2006), que são: equilíbrio, comparabilidade, exatidão, periodicidade, clareza e confiabilidade. O equilíbrio remete aos aspectos positivos e negativos do desempenho da organização; a comparabilidade refere-se à análise de mudanças ao passar do tempo pelos seus interessados; a exatidão se refere à informação precisa e detalhada; a periodicidade são as informações disponibilizadas a tempo de se tomar decisões; a clareza refere-se à compreensão e acessibilidade dos usuários; e a confiabilidade refere-se à qualidade e materialidade da informação disponível.

As informações divulgadas pelas empresas são de grande importância para os diferentes usuários (internos e externos). Atualmente, é crescente o número de empresas que divulgam informações ambientais em seus relatórios, demonstrando para o público-alvo o seu interesse em assuntos ambientais, assuntos esses que podem colocar a organização em posição favorável em relação à concorrência (Consoni et al., 2017).

Anualmente a Revista Exame divulga o Guia de Sustentabilidade que conta com as empresas mais sustentáveis, obedecendo alguns critérios elencados pela mesma. Tal guia é elaborado após as empresas se submeterem a alguns questionamentos.

A Revista Exame (Exame, 2012) catalogou 3 (três) mecanismos utilizados pelas empresas quando divulgam os seus relatórios: desenvolver uma estratégia de gestão voltada para o futuro, baseada em informações consistentes sobre os impactos positivos e negativos da sustentabilidade, tanto causados pela empresa como por fatores externos, tais como alterações climáticas ou questões de direitos humanos; melhorar o diálogo entre os acionistas, o que auxilia as empresas a identificar riscos e oportunidades ligados à sustentabilidade; e ajudar a mudar a mentalidade, buscando o que faz sentido para os negócios em um mundo dinâmico, onde importa não somente o âmbito financeiro, mas também o econômico, o social e o ambiental.

Com isso, os relatórios são de grande importância tanto para os usuários internos como externos de uma organização, de modo que possam vir a auxiliar desde a tomada de decisão internamente até a adesão de novos consumidores e investidores. Neles, encontram-se informações das empresas, o seu corpo institucional, metas, ideologias, investimentos e incentivos a determinadas áreas, com o intuito de fortalecer sua imagem e conquistar a confiança dos interessados. 


\subsection{Hipóteses de Pesquisa}

Frente aos estudos anteriores vê-se que os indicadores de desempenho são utilizados para mensuração dos investimentos realizados pelas empresas. Há uma concentração a atenção em mensurar o desempenho financeiro (Wernke \& Cláudio, 2003). De acordo com Epstein e Roy (2001), o desempenho de sustentabilidade leva a reações das partes interessadas que, por sua vez, melhoram as relações de desempenho financeiro.

Vital et al., (2009) analisaram comparativamente o desempenho financeiro das empresas que fazem parte do Índice de Sustentabilidade Empresarial (ISE) e as que não fazem parte, e, concluíram que as empresas com melhor desempenho financeiro são as que não fazem parte do ISE.

Já Machado et al., (2012) verificaram a existência de relação entre investimentos socioambientais e a inclusão das empresas no ISE. Concluíram que existe relação entre investimentos socioambientais e o ingresso das empresas na carteira ISE, demonstrando que os investimentos das empresas realizados e evidenciados em questões socioambientais é um indício de comprometimento real com a responsabilidade social e sustentabilidade.

Patari et al., (2011) analisaram a associação entre o desempenho financeiro e o desenvolvimento sustentável nas empresas listadas no Índice de Sustentabilidade Dow Jones. Os autores encontraram evidências positivas da relação entre as duas variáveis, principalmente nas empresas que medem o desempenho através da capitalização de mercado.

Melo, Almeida e Santana (2012) buscaram identificar o quanto os indicadores de 252 desempenho de empresas de papel e celulose podem afetar a inserção delas no ISE. Os resultados apontam que os indicadores financeiros são significativos e influenciam positivamente na participação do Índice.

Cavenaghi et al., (2019) almejaram estabelecer uma relação entre a adoção de responsabilidade social corporativa e desempenho econômico e/ou financeiro de empresas que faziam, e empresas que não faziam, parte do ISE. Foi identificado que as empresas que faziam parte do ISE mostraram maiores retornos médios e menores riscos, medido pelo desvio padrão, indicando um crescimento de seus ganhos quando comparados às outras empresas, não pertencentes ao ISE.

Vê-se que as empresas buscam manter seus resultados crescentes e se manterem legítimas. Observa-se que os resultados empresariais tendem a ser influenciados pelo nível de sustentabilidade empresarial, demonstrando que as empresas que se apresentam mais sustentáveis tendem a garantir maiores retornos.

Com isto, como o objetivo geral da pesquisa é utilizar os modelos propostos por Epstein e Roy, o modelo de 2001 onde os autores determinam quais as variáveis apresentam relação com o nível de evidenciação socioambiental empresarial e o modelo de 2003 que propõe a divisão das 4 (quatro) dimensões socioambientais juntamente com os possíveis níveis correspondentes, ainda não utilizados em empresas brasileiras, para observar o desempenho financeiro através dos indicadores financeiros e dos níveis de sustentabilidade no longo prazo, desenvolve-se a seguinte hipótese: 
$\mathbf{H}_{1}$ : Maiores níveis de evidenciação socioambiental induzem a melhores resultados financeiros futuros.

De acordo com Melo, Almeida e Santana (2012), estima-se que as empresas são impulsionadas muitas vezes a atingir atributos de legitimidade como forma de garantir aos stakeholders que as ações empresariais estão respondendo a padrões estabelecidos pelos órgãos legitimadores, como a ISE.

De modo geral, percebe-se que a questão socioambiental apresenta certa relevância mediante os resultados financeiros, assim como a participação das empresas em índices de sustentabilidade. Com isto, nota-se que a questão sustentável pode ser fator determinante para bons retornos, mediante boas perspectivas dos usuários da informação com a percepção ambiental da gestão.

Tendo em vista essa perspectiva, acredita-se que ao observar melhoras nos resultados financeiros a partir de atitudes legítimas, geralmente atribuídas a questões socioambientais, os gestores tendem a investir com maior ênfase em atributos legais. Baseando-se nisso, define-se a seguinte hipótese:

$\mathbf{H}_{2}$ : Melhores resultados financeiros induzem a maiores níveis de evidenciação sustentável futuros.

As hipóteses apresentadas têm como objetivo confirmar os estudos realizados pelos autores, indicando que as empresas as quais possuem interesse em práticas e ações sustentáveis, possuem um bom desempenho financeiro no longo prazo e que tais resultados os influenciam a investir em melhores práticas socioambientais. Existindo assim, uma relação entre os indicadores financeiros que estão sendo estudados e os níveis de sustentabilidade que foram analisados.

\section{PROCEDIMENTOS METODOLÓGICOS}

\subsection{Universo e Amostra}

O universo, objeto deste estudo, foi composto pelas empresas listadas no Guia de Sustentabilidade da Revista Exame, considerando o período de 2007 a 2017. A amostra final foi composta por 30 (trinta) empresas de capital aberto que permaneceram no guia durante os 10 (dez) anos pesquisados.

Essas empresas foram selecionadas devido à importância e interesse de fazer parte deste Guia e por serem companhias brasileiras de capital aberto, podendo assim ter acesso às informações necessárias para o desenvolvimento desta pesquisa.

Para a realização desse estudo, foram desenvolvidas análises de conteúdo, examinando Relatórios de Sustentabilidade (compreendendo Relato Integrado e Relatório Anual) publicados no sítio das instituições. Com isso, as variáveis investigadas em relação 
aos níveis de sustentabilidade foram elencadas de acordo com o modelo proposto por Epstein e Roy (2003), que são: meio ambiente, saúde e segurança, comunidade e empregados.

Com relação ao desempenho financeiro, as informações foram coletadas através das bases de dados: Thomson Reuters e Economática referentes ao período de 2007 a 2017 das empresas, no que se refere aos dados disponíveis em suas demonstrações para os cálculos dos seguintes indicadores financeiros: ROI, ROCE e EVA, sugeridos por Epstein e Roy (2001) para explicar o desempenho financeiro das empresas em relação à sustentabilidade.

\subsection{Definição das Variáveis}

Para a classificação da variável relacionada ao nível de sustentabilidade empresarial, a abordagem qualitativa se deu através da análise de conteúdo feita nos relatórios de sustentabilidade, na qual se define como sendo a coleta de informações pré-definidas pelo pesquisador em documentos textuais (Creswell \& Clark, 2013). Posteriormente, foram elencados níveis quantitativos para alocar os dados qualitativos encontrados.

Foram analisadas as dimensões propostas pelo modelo de Epstein e Roy (2003) de cada empresa, relacionadas ao meio ambiente, saúde e segurança, comunidade e empregados. Cada dimensão poderia ser classificada em 1 (um) dos 4 (quatro) níveis propostos, dispostos conforme o Quadro 1.

Quadro 1 - Demonstração da Análise de Conteúdo e do Sistema de Pontuação.

\begin{tabular}{|c|c|c|c|c|}
\hline Dimensões & Níveis & Descrição & Pontuação & $\begin{array}{c}\text { Total } \\
\text { Estimado }\end{array}$ \\
\hline \multirow{4}{*}{$\begin{array}{l}\text { 冈 Meio Ambiente; } \\
\text { 囚Saúde e Segurança; } \\
\text { 囚Comunidade; } \\
\text { Empregados; }\end{array}$} & Nível 1 & $\begin{array}{l}\text { Informação não associada ao desempenho } \\
\text { financeiro. }\end{array}$ & 1 & \multirow{4}{*}{16} \\
\hline & Nível 2 & $\begin{array}{l}\text { Informação quantificada, não associada ao } \\
\text { desempenho financeiro. }\end{array}$ & 2 & \\
\hline & Nível 3 & $\begin{array}{l}\text { Informação monetária sobre as despesas, } \\
\text { parcialmente associada ao desempenho financeiro. }\end{array}$ & 3 & \\
\hline & Nível 4 & $\begin{array}{l}\text { Informação monetária sobre os benefícios da } \\
\text { despesa (medidas de benefícios além dos custos), } \\
\text { totalmente associadas ao desempenho financeiro. }\end{array}$ & 4 & \\
\hline
\end{tabular}

Fonte: Adaptado de Epstein e Roy (2003).

O nível 1 está relacionado apenas às descrições das atividades relacionadas ao desempenho da sustentabilidade; o nível 2 fornece dados quantitativos, descrevendo as ações de sustentabilidade. Esses dois níveis descritos anteriormente não estão relacionados com o desempenho financeiro da organização, pois não informam despesas, custos e nem os benefícios usados para adesão destes; o nível 3 oferece informações monetárias em relação à adesão (despesa) de investimentos destinados aos impactos ambientais; e o nível 4 oferece informações referentes aos custos e os benefícios de atividades relacionadas ao meio ambiente. Com isso, observa-se que esses dois últimos níveis descritos sugerem uma interação mais completa no tocante ao desempenho financeiro das empresas.

Portanto, a pontuação total é considerada de acordo com o somatório dos pontos atribuídos a cada uma das dimensões analisadas, podendo ter um total de 16 (dezesseis), caso cada dimensão tenha sua pontuação máxima de 4 (quatro). 
Para mensurar tal variável, o total observado de pontos por cada empresa foi dividido pelo valor máximo que poderia ser atingido (16), gerando assim o valor de $S U S T_{\mathrm{it}}$, proxy que reflete o nível sustentabilidade empresarial.

As variáveis financeiras foram estimadas baseadas em Epstein e Roy (2001), que determinaram indicadores que explicam o desempenho financeiro da organização, frente à sustentabilidade com relação ao futuro. Tais indicadores foram o ROI, ROCE e EVA. Apesar de determinar estes indicadores, os autores não detalham fórmulas específicas que devem ser utilizadas. Dessa forma, por meio da literatura existente, utilizou-se o ROI baseado em Vieira et al. (2012), o ROCE e o EVA® baseados em Girão, Machado e Callado (2013), definidas no Quadro 2.

Quadro 2 - Definição das Variáveis ROI, ROCE e EVA.

\begin{tabular}{|l|c|l|l|c|}
\hline \multicolumn{1}{|c|}{ Variável } & Sigla & \multicolumn{1}{|c|}{ Cálculo } & \multicolumn{1}{|c|}{ Aplicação } & Referências \\
\hline $\begin{array}{l}\text { Valor Econômico } \\
\text { Adicionado }\end{array}$ & EVA $^{{ }}{ }_{\mathrm{i}}$ & $\begin{array}{l}\text { (NOPAT - Custo Total do } \\
\text { Capital) / Número de } \\
\text { Ações }\end{array}$ & $\begin{array}{l}\text { Demonstra a criação de valor ou } \\
\text { custo de oportunidade do capital } \\
\text { aplicado, que possa compensar os } \\
\text { riscos do negócio. }\end{array}$ & $\begin{array}{l}\text { Epstein e Roy (2001); } \\
\text { Vieira et al. (2012) }\end{array}$ \\
\hline $\begin{array}{l}\text { Retorno sobre o } \\
\text { Investimento }\end{array}$ & ROI $_{\mathrm{i}}$ & $\begin{array}{l}\text { Lucro Operacional / } \\
\text { (Passivos Onerosos }+ \\
\text { Patrimônio Líquido) }\end{array}$ & $\begin{array}{l}\text { Permite observar o quanto } \\
\text { se perde ou se ganha com os } \\
\text { investimentos realizados. }\end{array}$ & $\begin{array}{l}\text { Epstein e Roy (2001); } \\
\text { Girão, Machado e } \\
\text { Callado (2013). }\end{array}$ \\
\hline $\begin{array}{l}\text { Retorno do Capital } \\
\text { Empregado }\end{array}$ & ROCE $_{\mathrm{i}}$ & $\begin{array}{l}\text { Lucro Operacional / } \\
\text { (Ativo Total - Passivo } \\
\text { Circulante) }\end{array}$ & $\begin{array}{l}\text { Avalia a aplicação de capital para } \\
\text { a geração de lucro. }\end{array}$ & $\begin{array}{l}\text { Epstein e Roy (2001); } \\
\text { Girão, Machado e } \\
\text { Callado (2013). }\end{array}$ \\
\hline
\end{tabular}

Fonte: elaborada pelos autores (2020).

Para a realização do cálculo do EVA, foi necessário calcular o NOPAT, que foi obtido por meio da soma do lucro líquido com as despesas financeiras, deduzido das receitas financeiras, dividido pelo número de ações [NOPAT = (Lucro Líquido + Despesas Financeiras - Receitas Financeiras) / Número de Ações] (Girão et al., 2013).

De acordo com as hipóteses de pesquisa, criou-se a perspectiva de que tais variáveis financeiras apresentassem relação direta, ou positiva, com a variável referente ao nível de sustentabilidade empresarial, o que responderia aos achados teóricos que afirmam que maiores indicativos de sustentabilidade responderiam a melhores resultados financeiros, assim como melhores resultados financeiros tendem a impulsionar maior transparência na sustentabilidade empresarial.

\subsection{Modelo Utilizado}

Para realização desse estudo, utilizou-se quatro modelos de regressão com dados em painel. Os três primeiros modelos são baseados na primeira hipótese de pesquisa, apresentando as variáveis financeiras como dependentes do nível de sustentabilidade empresarial no período $\mathrm{t}-1$.

$$
\begin{aligned}
& \text { EVA }_{i t}=\beta_{0}+\beta_{1} S U S T_{i t-1}+\beta_{3} \text { CRISE }_{i t}+\beta_{4} \sum S E T_{i t}+\beta_{5} \sum A N O_{i t}+\mu_{i t} \\
& \text { ROI }_{i t}=\beta_{0}+\beta_{1} S U S T_{i t-1}+\beta_{3} C R I S E_{i t}+\beta_{4} \sum S E T_{i t}+\beta_{5} \sum A N O_{i t}+\mu_{i t} \\
& \text { ROCE }_{i t}=\beta_{0}+\beta_{1} S U S T_{i t-1}+\beta_{3} C R I S E_{i t}+\beta_{4} \sum S E T_{i t}+\beta_{5} \sum A N O_{i t}+\mu_{i t}
\end{aligned}
$$


O quarto modelo proposto corresponde à segunda hipótese de pesquisa, ao qual a variável dependente passa a ser o nível de sustentabilidade empresarial e as variáveis financeiras do período t-1 como variáveis de interesse da equação.

$$
\mathrm{SUST}_{\mathrm{it}}=\beta_{0}+\beta_{1} E V A_{\mathrm{it}-1}+\beta_{2} R O C E_{\mathrm{it}-1}+\beta_{3} R O I_{\mathrm{it}-1}+\beta_{4} G O V_{\mathrm{it}}+\beta_{5} \sum S E T_{\mathrm{it}}+\beta_{6} \sum A N O_{\mathrm{it}}+\mu_{\mathrm{it}}(4)
$$

\section{Em que:}

- $\quad C R I S E_{\text {it }}$ representa uma dummy que identifica os períodos de recessão financeira no Brasil. Sendo atribuído valor 1 para os anos de 2008, 2014, 2015 e 2016, e valor 0 aos demais anos. Estima-se que empresas tendem a ter baixos resultados em períodos de crise econômico-financeira (Silva, Santos, Perobelli \& Nakamura, 2016) - relação negativa com as variáveis financeiras;

- $\mathrm{GOV}_{i t}$ configura-se como uma dummy, em que o valor 1 é atribuído a empresas que se apresentam em algum dos níveis de governança, e 0 para aquelas que não apresentem. A governança corporativa tendencia as empresas a estarem mais voltadas a manterem boas práticas de sustentabilidade (Chan, Watson \& Woodliff, 2014) - relação positiva com a variável de sustentabilidade;

- $\quad \sum S E T_{\text {it }}$ e $\sum A N O_{\text {it }}$ são variáveis de controle estatístico, que podem captar peculiaridades diversas em relação aos setores do mercado brasileiro e dos anos da amostra. Os anos foram codificados de acordo com os seus valores numéricos e os setores conforme o Padrão Global de Classificação da Indústria (GICS Sector Name), com base na Thomson Reuters Eikon® (Graafland \& Noorderhaven, 2018) - variáveis de controle estatístico.

Dessa forma, mediante tais modelos, foi possível identificar se o nível de sustentabilidade socioambiental estaria relacionado a melhores resultados sobre o EVA, ROCE e ROI em período posterior. Assim como, foi possível analisar se tais indicadores são determinantes para que as empresas melhorem seu nível de sustentabilidade no período seguinte.

\subsection{Procedimentos Estatísticos}

Para melhor estimação dos parâmetros, foram realizados alguns testes. O Teste de Chow foi utilizado para observar a melhor estimação entre o Efeito Pooled Ordinary Least e o Efeito Fixo (OLS); o Teste de Hausman possibilitou comparação entre o Efeito Fixo (OLS) e o Efeito Aleatório (GLS); e o Teste de Breuch and Pagan comparou o Efeito Pooled e o Efeito Aleatório (GLS).

Após a especificação do melhor modelo de estimação, foram realizados o Teste de Breuch and Pagan para detectar a presença de heterocedasticidade entre os dados; o Teste de VIF para captar multicolinearidade; o Teste de Wooldridge para identificar autorrelação; e o Teste de Jarque Bera para verificar a normalidade dos dados.

Por meio da estatística descritiva, o desvio padrão das variáveis não apresentou altos valores, com isto, identificou-se a não presença de outliers na amostra, não sendo necessário o processo de winsorização. 
Como resposta aos testes, viu-se que apenas o modelo 1 apresentou melhor estimação por efeito Pooled e não normalidade entre seus dados, porém com pressuposto relaxado de acordo com o Teorema do Limite Central. Já os modelos 2, 3 e 4 foram estimados por Efeito Aleatório, apresentando normalidade em seus dados, porém com a presença de heterocedasticidade. Para todos os modelos foi detectada a presença de autocorrelação, sendo este problema corrigido, assim como para a heterocedasticidade, por meio da estimação de regressões robustas. Não se identificou multicolinearidade entre os dados.

\section{APRESENTAÇÃO E DISCUSSÃO DOS RESULTADOS}

\subsection{Estatística Descritiva e Modelo de Regressão}

Para retratar a visão geral dos dados, foi elaborada a Tabela 1 em que constam os resultados da estatística descritiva das 30 (trinta) empresas, considerando o período de 2007 a 2017.

Tabela 1 - Estatística descritiva dos anos de 2007 a 2017

\begin{tabular}{l|cccccc}
\hline \multicolumn{1}{c|}{ Indicadores } & SUST $_{i t}$ & EVA $_{\text {it }}$ & ROI $_{i t}$ & ROCE $_{\text {it }}$ & CRISE $_{\text {it }}$ & GOV $_{\text {it }}$ \\
\hline Média & 0,5516 & 0,0001 & 0,2899 & 0,1549 & 0,40 & 0,6333 \\
Mediana & 0,5625 & 0,0001 & 0,2454 & 0,1307 & 0 & 1 \\
Desvio Padrão & 0,1447 & 0,0008 & 0,3166 & 0,1132 & 0,4907 & 0,4827 \\
Mínimo & 0,2500 & $-0,0002$ & $-0,2408$ & $-0,1303$ & 0 & 0 \\
Máximo & 0,8125 & 0,0141 & 3,7923 & 0,6083 & 1 & 1 \\
\hline
\end{tabular}

Fonte: dados da pesquisa (2020).

De imediato, observa-se que as empresas apresentam níveis variados de evidenciação sobre responsabilidade socioambiental, apresentando uma média que especifica bem que há um equilíbrio entre grandes divulgadoras e menos divulgadoras sobre questões socioambientais. O EVA apresentou valores muito baixos para todas as empresas, demonstrando que o valor econômico agregado não oscila tanto.

Observando o ROI, pela média, verifica-se que a maioria das empresas se encontra em situação ruim, baixos retornos, já que o valor médio obtido se aproximou mais do valor mínimo do que do valor máximo encontrado, sendo confirmado pelo seu valor mediano. $O$ ROCE demonstrou que grande parte da amostra se apresenta com resultados baixos em relação ao retorno sobre o capital empregado, o que se confirma ao valor da mediana.

Percebe-se que $40 \%$ do período da amostra compreendeu anos de recessão econômica; além disso, 63,33\% das empresas da amostra apresentam-se registradas em algum dos três níveis de governança corporativa, de acordo com a B3.

Ao realizar os cálculos das primeiras regressões, foram inferidos resultados que competem à primeira hipótese de pesquisa, ao qual investida se as variáveis financeiras poderiam ser influenciadas pelo nível de divulgação de informações socioambientais. Os resultados são apresentados na Tabela 2. 
Foi realizado o Teste de Chow, Hausman e Breuch and Pagan para identificar se as regressões se adequariam ao Modelo de Efeito Pooled, ao Modelo de Efeitos Fixos (OLS) ou ao modelo de Efeitos Aleatórios (GLS). Viu-se que apenas o modelo 1 foi melhor estimado por Efeito Pooled, enquanto os modelos 2 e 3 se adequaram a estimação por Efeitos Aleatórios.

Pelo Teste de Jarque-Bera, vê-se que apenas os resíduos dos modelos 1 não se comportaram de maneira normal, porém tal pressuposto foi relaxado, baseado no Teorema do Limite Central. Já o Teste de Breuch and Pagan demonstrou que só o primeiro modelo apresentou homocedasticidade entre os dados. Quanto ao Teste de Wooldrige, viu-se que nos três casos os dados se mostraram autocorrelatos. Com isso, para a obtenção de dados mais consistentes, foi realizada a estimação de regressões robustas para melhor obtenção dos parâmetros.

Tabela 2 - Resultado da Regressão dos Três Primeiros Modelos

\begin{tabular}{c|ccc}
\hline Descrição & Modelo 1 & Modelo 2 & Modelo 3 \\
\hline SUST $_{\text {it-1 }}$ & 0,00006 & $0,7608^{* * *}$ & $0,1387^{* *}$ \\
CRISE $_{\text {it }}$ & $-0,0005^{* *}$ & $-0,1557^{* *}$ & $-0,0897^{* * *}$ \\
Constante & 0,00007 & 0,2117 & 0,0291 \\
\hline Teste de Chow & 0,4732 & 0,0000 & 0,0000 \\
Teste de Hausman & 1,0000 & 0,9997 & 1,0000 \\
Teste de Jarque-Bera & 0,0000 & 0,2647 & 0,1708 \\
VIF & 3,57 & 3,57 & 3,57 \\
Teste de Breuch and Pagan & 1,0000 & 0,0000 & 0,0000 \\
Teste de Wooldrige & 0,0000 & 0,0000 & 0,0000 \\
\hline Prob > Chi2 & 0,0008 & 0,0068 & 0,0000 \\
Within & 0,0357 & 0,0853 & 0,1696 \\
Between & 0,9949 & 0,1287 & 0,3980 \\
Overall & 0,1284 & 0,1022 & 0,3239 \\
\hline
\end{tabular}

Legenda: ${ }^{* *} 1 \%,{ }^{* *} 5 \%,{ }^{*} 10 \%$ de significância. Variáveis $\sum S E T_{i t}$ e $\sum A N O_{i t}$ estimadas como controle estatístico. Fonte: Resultados da Pesquisa (2020).

Os achados do Modelo 1 demonstraram que não houve significância estatística de relação entre a variável $E V A_{\text {it }}$ e o nível de divulgação socioambiental $\left(S U S T_{i t-1}\right)$. Já os Modelos 2 e 3 demonstraram que o nível de evidenciação socioambiental influenciou significativamente a $1 \%$ e $5 \%$, respectivamente, na variável $R O I_{i t}$ e $R O C E_{i t}$. Todos os modelos apresentaram-se significativos e adequados.

Tais resultados inferem que o nível de evidenciação de informações relacionadas à responsabilidade socioambiental corporativa influenciou o valor dos retornos sobre o capital empregado e o valor dos retornos sobre investimento das empresas da amostra, mantendo uma relação direta de determinação. Com isto, a primeira hipótese de pesquisa é confirmada apenas para as variáveis financeiras ROI e ROCE, corroborando com a perspectiva de Epstein e Roy (2001), sendo rejeitada para o EVA. Dessa forma, os achados de Cavenaghi et al., (2019) se alinham ao apresentado, pois demonstrou-se que maiores níveis de 
sustentabilidade proporcionaram maiores retornos sobre o capital investido, possibilitando assim lucros crescentes, indo de encontro também ao descoberto por Patari et al., (2011) e Melo, Almeida e Santana (2012).

Confirmou-se a perspectiva de Silva et al. (2016) ao constatar que a variável CRISE apresentou-se positivamente significante em relação a todas as variáveis financeiras, demonstrando que períodos de recessão econômica tendem a reduzir os resultados empresariais.

Em conformidade com a segunda hipótese proposta, foi estabelecido o modelo 4, ao qual contém as variáveis financeiras como explicativas para o nível de sustentabilidade empresarial, tendo seus resultados descritos na Tabela 3.

Viu-se que pelo Teste de Hausman, o modelo melhor se adequa a regressão por Efeitos Aleatórios (GLS); os resíduos se distribuem de maneira normal (Teste de Jarque-Bera); há heterocedasticidade pelos dados (Teste de Breuch and Pagan); e há autocorrelação (Teste de Wooldrige). Estimou-se o modelo de forma robusta para a correção de tais pressupostos. O modelo mostrou-se significativo a $1 \%$.

Tabela 3 - Resultado da Regressão do Modelo 4

\begin{tabular}{|c|c|}
\hline Descrição & Modelo 4 \\
\hline $\mathrm{EVA}_{\mathrm{it}-1}$ & 1,9041 \\
\hline $\mathrm{ROI}_{\mathrm{it}-1}$ & $0,0430^{* * *}$ \\
\hline $\mathrm{ROCE}_{\mathrm{it}-1}$ & $-0,0116$ \\
\hline $\mathrm{GOV}_{\mathrm{it}}$ & $0,0814^{* *}$ \\
\hline Constante & 0,3076 \\
\hline Teste de Chow & 0,0000 \\
\hline Teste de Hausman & 1,0000 \\
\hline Teste de Jarque-Bera & 0,8585 \\
\hline VIF & 2,59 \\
\hline Teste de Breuch and Pagan & 0,0000 \\
\hline Teste de Wooldrige & 0,0000 \\
\hline Prob $>$ Chi2 & 0,0000 \\
\hline Within & 0,4167 \\
\hline Between & 0,2056 \\
\hline Overall & 0,2961 \\
\hline
\end{tabular}

Legenda: ${ }^{* *} 1 \%,{ }^{* *} 5 \%,{ }^{*} 10 \%$ de significância

Variáveis $\sum S E T_{\text {it }}$ e $\sum A N O_{\text {it }}$ estimadas como controle estatístico.

Fonte: Resultados da Pesquisa (2019). 
Conforme resultados expostos, viu-se que apenas a variável $R O I_{\mathrm{it}-1}$ apresentou relação direta e estatisticamente significativa com o nível de evidenciação socioambiental a $1 \%$. As demais variáveis, $E V A_{\mathrm{it}-1}$ e $R O C E_{\mathrm{it}-1}$, não apresentaram influência significativa com a variável dependente.

Tal resultado expressa que aumentos no valor do retorno sobre o investimento tendem a influenciar no aumento de divulgação socioambiental pelos gestores, que pode estar associado à perspectiva de que a legitimidade seria o fator potencial para que os retornos fossem advindos da divulgação sobre sustentabilidade, fazendo com que essa aplicação fosse possível, de acordo com a perspectiva de Melo, Almeida e Santana (2012). Viu-se que a governança corporativa se mostrou determinante para a evidenciação da sustentabilidade empresarial, de acordo com a perspectiva de Chan et al. (2014).

Desse modo, ao associar o resultado de todos os modelos estimados, se pode identificar que o retorno sobre o investimento (ROI) pode ser considerado um fator determinante para que as empresas invistam em melhores níveis de sustentabilidade. Com isso, maiores níveis de sustentabilidade demonstraram possíveis aumentos no valor do retorno sobre o capital empregado (ROCE) e no retorno sobre investimentos (ROI) das empresas, o que faz com que a sustentabilidade empresarial seja um possível fator chave para as empresas que aplicarem essa perspectiva em suas operações.

\section{CONCLUSÕES}

O presente trabalho teve como principal objetivo verificar a relação do desempenho financeiro e da evidenciação de fatores de responsabilidade socioambiental, das empresas de capital aberto listadas no Guia de Sustentabilidade da revista Exame, considerando o período de 2007 a 2017. Analisou-se e pontuou-se, por meio dos relatórios de sustentabilidade, ações relacionadas ao meio ambiente, saúde e segurança, comunidade e empregados (que representam as pontuações dos níveis), observando se estão ligadas ao seu desempenho financeiro de longo prazo.

Os resultados encontrados não confirmaram em sua totalidade que o desempenho financeiro das empresas possui relação determinante com os níveis de sustentabilidade empresarial, tendo por base os indicadores propostos por Epstein e Roy (2003). De imediato, viu-se que as empresas participantes do Guia de Sustentabilidade da Revista Exame apresentam níveis variados de evidenciação socioambiental.

Ao observar se o nível de divulgação ambiental influenciava nos resultados financeiros, viu-se que apenas as variáveis ROI e ROCE apresentaram-se significantes, demonstrando que um aumento no nível de divulgação possivelmente impacta no aumento do valor dos retornos sobre o capital empregado e nos retornos sobre o capital investido. Desse modo, o Valor Econômico Adicionado não se mostrou influenciado por tal variável.

Quanto à influência das variáveis financeiras sobre o nível de divulgação socioambiental, viu-se que apenas o Retorno sobre o Investimento se mostrou determinante 
para que as empresas ampliassem sua visão socioambiental e as evidenciassem. Conforme achados, pôde-se inferir que o nível de divulgação socioambiental impacta no retorno sobre o capital empregado (ROCE) e no retorno sobre capital investido (ROI), e com isso, quanto mais os retornos sobre os investimentos (ROI) crescem, mais tendem a impulsionar as empresas a divulgarem mais informações.

Identifica-se que as empresas analisadas que participam do guia estão divulgando tais informações às partes interessadas, devido os níveis obtidos na análise. Por isso, investem em ações que melhorem a sua imagem e reputação dentro da sociedade. Com isso, observam-se informações mais claras e detalhadas em seus relatórios, que são capazes de descrever as ações das organizações, mesmo que haja algumas distinções.

No entanto, tal prática não demonstrou ser influenciada pelo valor econômico adicionado (EVA). Porém, observou-se que os retornos sobre os investimentos (ROI) determinaram maiores níveis de sustentabilidade. Com isso, questões ambientais geraram maiores retornos sobre o capital empregado (ROCE) e investido (ROI).

Dessa forma, as empresas impulsionam-se a provavelmente aumentar seu nível de evidenciação, buscando maximizar cada vez mais os retornos esperados. De forma geral, não foi possível confirmar que todas as variáveis propostas por Epstein e Roy (2003) influenciam as empresas a investirem em maiores níveis de evidenciação socioambiental, confirmando relação apenas com ROI e ROCE.

Reconhece-se que a prática de sustentabilidade e sua devida divulgação pode proporcionar melhores resultados em relação aos retornos oriundos de aplicações, além disso, a geração de lucro, a partir desse investimento, tende a ser mais presente. Notase que ao admitir maiores retornos baseados em sustentabilidade, tais empresas podem aplicar maiores investimentos futuros em sustentabilidade, tornando-se um ciclo baseado em possível legitimidade.

Tal achado possibilita aos gestores observarem melhor as oportunidades de investimento em questões socioambientais e os seus benefícios, assim como potenciais investidores podem adotar uma visão mais otimista em relação a empresas que trabalham com a sustentabilidade em suas operações.

Uma das limitações para a realização desta pesquisa foi a diversidade de informações em alguns relatórios das empresas analisadas, não apresentando de forma completa o conteúdo para classificá-lo de maneira mais rápida de acordo com o modelo executado. Como recomendação para futuras pesquisas, pode-se utilizar outros indicadores econômico-financeiros, assim como uma amostragem maior de empresas, com ampliação do tempo de estudo. 


\section{REFERÊNCIAS}

Ameer, R., \& Othmam, R. (2012). Sustainability Practices and Corporate Financial

Performance: A Study Based on the Top Global Corporations. Journal of Business Ethics, 108 (1), 61-79.

Bonsón, E., \& Bednárová, M. (2015). CSR reporting practices of Eurozone companies. Revista de Contabilidad, 18(2), 182-193.

Cavenaghi, F. B., Pimenta Júnior, T., Antônio, R. M., Lima, F. G., \& Corrêa, A. C. C. (2019). The Behavior of Brazilian Companies Shares Return under Social Responsibility. Revista de Negócios, 24(3), 49-61.

Chan, M. C., Watson, J., \& Woodliff, D. (2014). Corporate governance quality and CSR disclosures. Journal of Business Ethics, 125(1), 59-73.

Creswell, V. L., \& Clark, P. (2013). Pesquisa de métodos mistos. 2. ed. Porto Alegre: Penso

Coelho, A. L. D. A. L., Coelho, C., \& Godoi, C. K. (2013). O discurso da sustentabilidade e sua inserção no contexto organizacional. Revista Gestão \& Conexões, 2(1), 147-186.

Consoni, S., Colauto, r. D., \& Lima, G. A. S. F. (2017). A Divulgação Voluntária e o Gerenciamento de Resultados Contábeis: Evidências no Mercado de Capitais Brasileiro. Revista Contabilidade \& Finanças, 28(74), 249-263.

Epstein, M.J., \& M.-J. Roy. (2001). Sustainability in Action: Identifying and Measuring the Key Performance Drivers. Long Range Planning, 34, 585-604.

Epstein, M.J., \& M.-J. Roy. (2003). Making the Business Case for Sustainability Linking Social and Environmental Actions to Financial Performance. Journal of Corporate Citizenship, 9, 79-96.

Exame. (2012). Qual a importância dos relatórios de sustentabilidade. Disponível em: < https:// exame.abril.com.br/mundo/qual-e-a-importancia-dos-relatorios-de-sustentabilidade/>

Fernandes, F. Da S., Siqueira, J. R. M. De., \& Gomes, M. Z. (2010). A decomposição do modelo da Global Reporting Initiative (GRI) para a avaliação de relatórios de sustentabilidade. Biblioteca Digital. Revista do BNDS, 101-132.

Gao, L., \& Zhang, J. H. (2015). Firms' earnings smoothing, corporate social responsibility, and valuation. Journal of Corporate Finance, 32, 108-127.

Gil, A. C. (2002). Como Elaborar Projetos de Pesquisa. 4. ed. São Paulo: Atlas. 
Girão, L. F. A. P., Machado, M. A. V., \& Callado, A. L. C. (2013). Análise dos fatores que impactam o MVA das companhias abertas brasileiras: Será o EVA® mais Value Relevant que os indicadores de desempenho tradicionais? Sociedade, Contabilidade e Gestão, 8 (2), 89-105.

Graafland, J., \& Noorderhaven, N. (2018). National culture and environmental responsibility research revisited. International Business Review, 27(5), 958-968.

GRI - GLOBAL REPORTING INITIATIVE. Disponível em: <https://www.globalreporting. org/Pages/default.aspx>. Acesso em: 20 maio 2018.

Kansal, M., Joshi, M., \& Batra, G. S. (2014). Determinants of corporate social responsibility disclosures: Evidence from India. Advances in Accounting, 30(1), 217-229.

Kaplan, R.S. \& Norton, D.P. (1997)/ A estratégia em ação: Balanced Scorecard. 21. ed. São Paulo: Campus.

Kruter, G. E., Barcellos, M. D. De., \& Silva, V. S. Da. (2012). As Atitudes dos Consumidores em Relação ao Plástico Verde. Revista de Gestão Ambiental e Sustentabilidade: GeAS, 1 (1), 19-46.

Lokuwaduge, C. S. D. S., \& Heenetigala, K. (2017). Integrating environmental, social and governance (ESG) disclosure for a sustainable development: An Australian study. Business Strategy and the Environment, 26(4), 438-450.

Machado, M. A. V., Macedo, M. A. Da S., Machado, M. R., \& Siqueira, J. R. M. De. (2012). Análise da relação entre investimentos socioambientais e a inclusão de empresas no Índice de Sustentabilidade Empresarial - (ISE) da BM\&FBovespa. Revista de Ciências da Administração, 14 (32),141-156.

Marion, J. C. (2015). Contabilidade Básica. 11. ed. São Paulo: Atlas.

Mcdonagh, P. (1998). Towards a theory of sustainable communications. Journal of Marketing Management, Helensburgh, 14 (6), 591-622.

Melo, E. C. De., Almeida, F. M., \& Santana, G. A. Da S. (2012). Índice de sustentabilidade empresarial (ISE) e desempenho financeiro das empresas do setor de papel e celulose. Revista de Contabilidade e Controladoria, 4, (3), 95-112.

Munck, L., \& Souza, R. B. De. (2009). Gestão por Competências e Sustentabilidade Empresarial: em busca de um quadro de análise. Revista eletrônica Gestão e Sociedade, 3 (6), 254-287.

Nogueira, E. P., \& Faria, A. C. de. (2012). Sustentabilidade nos principais bancos brasileiros: uma análise sob a ótica da Global Reporting Initiative. Revista Universo Contábil, 8 (4), 119-139. 
Orlitzky, M., Schmidt, F. L., \& Rynes, S. L. (2003). Corporate social and financial performance: A meta-analysis. Organization Studies, 24(3), 403-441.

Patari, S., Jantunen, A., Kylaheiko, K., \& Sandstrom, J. (2011). Does Sustainable Development Foster Value Creation? Empirical Evidence from the Global Energy Industry. Corporate Social Responsibility and Environmental Management, 19(6), 317-326.

Pereira, A. F. A., Stocker, F., Mascena, K. M. C., \& Boaventura, J. M. G. (2020). Desempenho Social e Desempenho Financeiro em Empresas Brasileiras: Análise da Influência do Disclosure. Brazilian Business Review, 17(5), 540-558.

Pimenta, H. C. D. (2010). Sustentabilidade Empresarial: práticas em cadeias produtivas. Natal: IFRN Editora.

Silva, S. S. da. (2014). Proposal for a model to analyze commitment to sustainability. Ambiente \& Sociedade, São Paulo, 17 (3), 35-54.

Silva, N. P., Santi, R. B., Degraf, D. M., \& Silva, M. C. GD. (2013). Avaliação da sustentabilidade organizacional por meio das dimensões econômica, social e ambiental: um estudo de caso em uma empresa de energia elétrica na região Sul do Brasil. Revista ADMpg Gestão Estratégica, 6 (2), 33-41.

264 Silva, E. D. S., Santos, J. F. D., Perobelli, F. F. C., \& Nakamura, W. T. (2016). Capital Structure of Brazil, Russia, India and China by Economic Crisis. RAM. Revista de Administração Mackenzie, 17(3), 105-131.

Silva, A., Floriani, R., \& Hein, N. (2018). Influência do Desempenho Econômico-Financeiro nas Inovações Tecnológicas de Empresas Brasileiras de Capital Aberto da Construção Civil. Revista de Administração da UFSM, 11(4), 939-954.

Spezamiglio, B. Dos S., Galina, S. V. R., \& Calia, R. C. (2016). Competitiveness, innovation and sustainability: an inter- relationship through literature systematization. REAd. Rev. eletrôn. adm. Porto Alegre, 22 (2), 363-393.

Vieira, C. B. H. A., Verde, I. D. O. L., Bezerra, R. L., Rodrigues, P. N., \& Ismael, V. S. (2011, December). Índices de rentabilidade: um estudo sobre os indicadores ROA, ROI e ROE de empresas do subsetor de tecidos, calçados e vestuários listadas na BOVESPA. In VIII Convibra Administração-Congresso Virtual Brasileiro de Administração.

Vital, J. T.; Martins, C. M., Dalló, S., Oliveira, M. G., \& De Marino, C. A. (2009). A Influência da Participação no Índice de Sustentabilidade Empresarial (ISE) no Desempenho Financeiro das Empresas. Revista de Ciências da Administração, 11 (24), 11-40. 
Weber O, Scholz RW, \& Michalik GG. (2010). Incorporating sustainability criteria into credit risk management. Business Strategy and the Environment, 19, 39-50.

Wernke, R., \& Cláudio, D. A. (2003). Eva (Economic Value Added) versus ROI (Return on Investment). Revista Catarinense da Ciência Contábil, 3 (5), 29-41.

\section{Dados dos autores:}

\section{Emily Tavares Pessoa Maciel}

(iD) ORCID: https://orcid.org/0000-0001-6304-6653

Mestrado em Ciências Contábeis pelo Programa de Pós-Graduação em Ciências Contábeis da Universidade Federal da Paraíba. Professora Substituta do Curso de Bacharelado em Administração da Universidade Federal do Piauí (UFPI). Picos, Piauí, Brasil. E-mail: emilytavares@ymail.com.

\section{Francisco José da Silva Júnior}

(iD) ORCID: https://orcid.org/0000-0001-7954-6089

Mestrado em Ciências Contábeis pelo Programa de Pós-Graduação em Ciências Contábeis da Universidade Federal da Paraíba. Assistente Administrativo da Prefeitura Municipal de Sousa. João Pessoa, Paraíba, Brasil. E-mail: fjsilvajunior@hotmail.com.

\section{Maria Luiza Farias Diniz}

(iD) ORCID: https://orcid.org/0000-0002-2344-5614

Mestrado em Ciências Contábeis pelo Programa de Pós-Graduação em Ciências Contábeis da Universidade Federal da Paraíba. Bancária na Instituição Financeira Bradesco. João Pessoa, Paraíba, Brasil. E-mail: luiza farias@hotmail.com.

\section{Aldo Leonardo Cunha Callado}

(iD) ORCID: https://orcid.org/0000-0002-5393-6094

Doutorado em Agronegócios pela Universidade Federal do Rio Grande do Sul. Professor nos Programas de Pós-Graduação em Administração (PPGA) e em Ciências Contábeis (PPGCC) da Universidade Federal da Paraíba e no Programa de Pós-Graduação em Controladoria (PPGC) da Universidade Federal Rural de Pernambuco. João Pessoa, Paraíba, Brasil. E-mail: aldocallado@yahoo.com.br.

\section{Como citar este artigo:}

Maciel, E. T. P., Júnior, F. J. S., Diniz, M. L. F., \& Callado,A. L. C. (2021). Relação entre Desempenho Financeiro e Evidenciação Socioambiental à Luz do Modelo de Epstein e Roy. AOS - Amazônia, Organizações e Sustentabilidade, 10(2). http://dx.doi.org/10.17648/aos.v10i2.2133 